Kumawula, Vol. 3, No.2, Agustus 2020, Hal 348 - 357 DOI: https://doi.org/10.24198/kumawula.v3i2.28534

ISSN 2620-844X (online)

Tersedia online di http://jurnal.unpad.ac.id/kumawula/index

\title{
EVALUASI PELATIHAN PEMBUATAN FORECASTING UNTUK PERANCANGAN PRODUK BERORIENTASI PASAR DENGAN MINITAB KEPADA KARANG TARUNA DI BEKASI
}

\author{
Joko Riyono $^{1^{*}}$, Christina Eni Pujiastuti ${ }^{2}$ \\ ${ }^{1,2}$ Progam Studi Teknik Mesin FTI, Universitas Trisakti \\ *jokoriyono@trisakti.ac.id
}

\begin{abstract}
ABSTRAK
Forecasting merupakan salah satu metode di dalam statistik yang digunakan untuk melakukan pendugaan atau perkiraan tentang terjadinya suatu peristiwa atau trend yang akan berlaku di masa yang akan datang.Forecasting ini sangat bermanfaat di berbagai bidang kehidupan khususnya di dunia kerja.Salah satu manfaat tersebut diantaranya sesuai dengan judul progam Pengabdian Kepada Masyarakat (PKM) yang penulis ambil, adalah dalam perancangan produk .Sebagai upaya pengenalan dan pemberian pemahaman aplikasi metode forecasting dengan software minitab kepada para pemuda karang taruna baik yang telah bekerja ataupun yang belum khususnya di daerah Bekasi sebagai bekal dan tambahan pengetahuan nantinya di dunia kerja ,maka progam PKM ini diberikan kepada mereka.Harapan dari pemberian progam ini kemampuan dan pengetahuan mereka tentang aplikasi forecasting di perancangan produk dapat bertambah .Pada progam ini materi disampaikan dengan metode diskusi,tanya jawab disertai studi kasus serta bagaimana cara menyelesaikannya menggunakan software minitab .Berdasarkan hasil nilai pre test dan post test yang diberikan kepada peserta dapat disimpulkan bahwa progam ini terbukti dapat meningkatkan pemahaman peserta mengenai forecasting diperancangan produk terlihat dari rata rata jawaban benar Pre test sebesar 10,591 menjadi 13,5 dengan skala penilaian 15,serta kuesioner yang memberikan kesimpulan bahwasannya jawaban peserta memberikan indeks penilaian sebesar 78,72\% Skala Likert terhadap pelatihan ini.
\end{abstract}

\begin{abstract}
Forecasting is one of the methods in statistics used to estimate or estimate the occurrence of an event or trend that will apply in the future. Forecasting is very useful in various fields of life, especially in the world of work. One of the benefits is in accordance with The title of the Community Service Program (PKM) that the writer took, was in product design. As an effort to introduce and provide understanding of the application of forecasting methods with Minitab software to youth cadets, both those who have worked or those who have not, especially in the Bekasi area as a provision and additional knowledge later in the world of work, the PKM program is given to them. Hope from the provision of this program their ability and knowledge of forecasting applications in product design can increase. how to solve it using Minitab software. Based on the results of the pre-test and post-test scores given to the participants, it can be concluded that this program is proven to be able to increase participants' understanding of forecasting in product design as seen from the average pre-test correct answers of 10,591 to 13.5 with a rating scale of 15 , as well as a questionnaire that provides a conclusion that the participants' answers provided an assessment index of $78.72 \%$ Likert Scale towards this training.
\end{abstract}

Keywords: Forecasting; Product Design ; Likert Scale 


\section{PENDAHULUAN}

Forecasting sebagai salah satu metode yang ada di ilmu statistik banyak digunakan untuk melakukan pendugaan atau perkiraan tentang terjadinya suatu peristiwa atau trend yang akan berlaku di masa yang akan datang.Forecasting ini sangat bermanfaat di dalam berbagai bidang kehidupan,diantaranya di dalam perancangan produk.Sesuai dengan judul progam Pengabdian Kepada Masyarakat (PKM) yang penulis ambil, nantinya akan diberikan teori dan studi kasus di forecasting untuk perancangan produk menggunakan software minitab.Sasaran dari progam PKM ini adalah para pemuda baik yang telah bekerja ataupun yang belum khususnya di daerah Bekasi.

Latar belakang pendidikan peserta yang hanya sampai pada Sekolah Menengah Tingkat Atas dimana pengetahuan tentang teori ilmu statistik masih sangat kurang dikarenakan bekal yang diperoleh saat di sekolah sangat minim, kemudian belum terbiasanya mereka mempraktekkan kedalam progam yang ada pada software minitab sebagai alat bantu penyelesaian kasus kasus statistik menjadi salah satu kendala didalam penyampaian materi terutama diforecasting data menggunakan software minitab.Semua itu tercermin dari hasil nilai pre test yang diberikan kepada peserta sebelum pemberian latihan.

Sejalan dengan tujuan yang telah disampaikan yaitu agar kemampuan dan pengetahuan para peserta tentang aplikasi forecasting di perancangan produk menggunakan progam yang ada pada software minitab dapat bertambah, kami melakukan peningkatan pemahaman para peserta menggunakan metode diskusi,tanya jawab disertai studi kasus pada masalah perancangan produk berorientasi pasar serta bagaimana cara menyelesaikannya memakai software minitab secara langsung di PC atau laptop.Menurut riset yang telah dilakukan oleh Royani dkk.(2018),Pemakaian metode praktek secara langsung yang diterapkan pada sasaran didik dalam hal ini peserta PKM dapat memberikan pengaruh terhadap ketrampilan proses sains dan kemampuan berpikir kritis peserta didik .Hal ini dapat terjadi dikarenakan pada pemberian metode praktek secara langsung akan membangkitkan motivasi peserta didik,mengembangkan ketrampilan dasar melakukan uji coba dan membuat proses kegiatan diskusi lebih terarah pada proses pembahasan materi yang bersifat konkrit disebabkan peserta dapat berdiskusi dengan peserta yang lain sehingga akan diperoleh ide,gagasan ataupun konsep yang baru.Target dari praktek secara langsung adalah agar peserta dapat membuktikan kebenaran dari teori-teori konsep yang berlaku dan mendapatkan rasa kepuasan dari hasil proses belajarnya (Nisa 2017).Oleh karena itu peneliti menerapkan metode praktek secara 
langsung menggunakan software minitab dalam memberi pemahaman teori statistik khususnya tentang forecasting melalui pendekatan aplikasi terhadap perancangan produk dengan harapan membantu peserta agar dapat lebih memahami aplikasi tersebut dan penerapannya di dunia kerja .

\section{METODE}

Sebagai akibat wabah Covid 19 yang melanda hampir seluruh wilayah Indonesia dan diberlakukannya Pembatasan Sosial Berskala Besar (PSBB) disejumlah wilayah maka pelatihan ini dilakukan secara daring ( online) menggunakan Aplikasi Zoom pada Hari/Tanggal: Minggu /17 Mei 2020. Penyampaian materi lewat metode daring dengan Zoom diikuti diskusi,tanya jawab serta pemberian studi kasus aplikasi forecasting pada perancangan produk dan penyelesaiannya menggunakan software minitab.Pelatihan diikuti oleh 22 peserta yang berasal dari daerah Bekasi dan sekitarnya.

Disamping itu agar tingkat keberhasilan pelatihan ini nantinya dapat terukur secara kuntitatif maka dilakukan pula pemberian pre test kepada peserta yang diberikan sebelum pelatihan dan post test yang diberikan setelah pelatihan ,dimana soal pre test dan post test sama dari sini nantinya dapat terlihat kemampuan dan pengetahuan para peserta saat sebelum ikut pelatihan dan setelah mengikuti pelatihan.Untuk mengukur tingkat kepuasan peserta PKM terhadap isi pelatihan dan kinerja instruktur, kami memberikan umpan balik kuesioner yang diisi oleh peserta setelah pelatihan selesai.Kuesioner yang diberikan kepada peserta mengharuskan mereka untuk menunjukkan tingkat persetujuannya terhadap serangkaian pertanyaan ,selanjutnya jawaban atau pendapat mereka diukur dengan skala Likert.Tingkat persetujuan yang dimaksud dalam Skala Likert terdiri atas 5 pilihan skala gradasi yaitu Sangat Setuju, Setuju, Ragu-ragu, Tidak Setuju, Sangat Tidak Setuju. Kemudian hasil Skala Likert diolah menggunakan analisis interval,agar jawaban kuesioner dapat dihitung dalam bentuk kuantitatif maka jawaban-jawaban dari peserta tersebut diberi bobot nilai atau skor likert sebagai berikut:

- Sangat Setuju diberi nilai 5

- $\quad$ Setuju diberi nilai 4

- Ragu-Ragu diberi nilai 3

- Tidak Setuju diberi nilai 2

- Sangat Tidak Setuju diberi nilai 1 
Selanjutnya dihitung Total Skor Nilai yang didapat setiap peserta dari setiap pertanyaan dan Indeks (\%) nya dengan rumus:

Indeks(\%) $=\frac{\text { Total Skor }}{\text { Skor maksimum }} \times 100 \%$

Kesimpulan pendapat peserta didasarkan pada nilai indeks (\%) berada dalam interval penilaian berikut:

Indeks 0\%-19,99\% :Sangat Tidak Setuju STS

Indeks 20\%-39,99\% : Tidak Setuju

Indeks 40\%-59,99\% :Ragu-ragu

Indeks 60\%-79,99\% :Setuju

Indeks 80\%-100\% :Sangat Setuju

\section{HASIL DAN PEMBAHASAN}

Seperti disampaikan pada bagian sebelumnya bahwa agar tingkat keberhasilan pelatihan ini nantinya dapat terukur secara kuntitatif maka dilakukan pula pemberian pre test dan post test .Adapun pertanyaan yang diajukan di pre test dan post test adalah sebagai berikut:

\section{Tabel 1. Pre Test Dan Post Test}

\begin{tabular}{|c|c|c|}
\hline Pernyataan & Benar & Salah \\
\hline 1. Analisa regresi adalah salah satu metode di statistik. & & \\
\hline $\begin{array}{l}\text { 2. Analisa Regresi Digunakan untuk melihat hubungan diantara satu atau } \\
\text { lebih variabel dalam persamaan matematika. }\end{array}$ & & \\
\hline $\begin{array}{l}\text { 3. Analisa Regresi dapat digunakan untuk mengestimasi nilai suatu variabel } \\
\text { tak bebas dengan diketahui nilai sebarang variabel bebasnya . }\end{array}$ & & \\
\hline $\begin{array}{l}\text { 4. Analisa regresi hanya dapat digunakan untuk menentukan nilai variabel } \\
\text { tak bebas jika nilai variabel bebas berada dalam selang interval nilai } \\
\text { minimum dan maksimum variabel bebas. }\end{array}$ & & \\
\hline $\begin{array}{l}\text { 5. Forecasting adalah salah satu metode estimasi di statistik yang dikenal } \\
\text { juga dengan peramalan. }\end{array}$ & & \\
\hline $\begin{array}{l}\text { 6. Forecasting tidak dapat digunakan untuk mengestimasi nilai variabel tak } \\
\text { bebas jika nilai variabel bebas berada dalam selang interval nilai minimum } \\
\text { dan maksimum variabel bebas. }\end{array}$ & & \\
\hline $\begin{array}{l}\text { 7. Forecasting tidak dapat digunakan untuk mengestimasi nilai variabel tak } \\
\text { bebas jika nilai variabel bebasnya berada di luar rentang nilai minimum } \\
\text { dan maksimum variabel bebas. }\end{array}$ & & \\
\hline 8. Jumlah data tidak mempengaruhi hasil forecasting & & \\
\hline $\begin{array}{l}\text { 9. Semakin sedikit data yang digunakan hasil forecasting semakin baik } \\
\text { karena tidak rumit. }\end{array}$ & & \\
\hline 10. Semakin banyak data yang digunakan hasil forecasting akan semakin baik & & \\
\hline 11. Hasil forecasting selalu sama dengan kenyataan & & \\
\hline $\begin{array}{l}\text { 12. Ukuran untuk melihat model forecasting yang paling cocok dengan } \\
\text { kenyataan adalah dengan melihat ukuran MAPE (Mean Absolute } \\
\text { Percentage Error), MAD (Mean Absolute Deviation), atau MSD (Mean } \\
\text { Square Deviation). }\end{array}$ & & \\
\hline 13. Semakin besar nilai MAPE (Mean Absolute Percentage Error), MAD & & \\
\hline
\end{tabular}


(Mean Absolute Deviation), atau MSD (Mean Square Deviation) maka model forecastingnya paling baik.

14. Semakin kecil nilai MAPE (Mean Absolute Percentage Error), MAD (Mean Absolute Deviation), atau MSD (Mean Square Deviation) maka model forecastingnya paling baik.

15. Forecasting digunakan untuk mengetahui trend yang akan terjadi pada waktu akan datang didasarkan data yang ada pada saat lampau.

Terlihat di sini ada 15 pertanyaan,kemudian jawaban tiap peserta pelatihan kami kumpulkan dan diperoleh sebaran jumlah jawaban benar dari peserta pelatihan seperti terangkum dalam gambar berikut sebagai hasil olahan menggunakan minitabv17:

1.Hasil Pre Test.

Descriptive Statistics: Nilai Pre Test

Variable N N* Mean SE Mean StDev Minimum Q1 Median Q3 Maximum

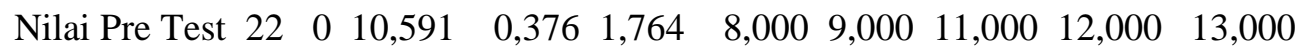

Gambar 1. Histogram Sebaran Jawaban Benar Pre Test.

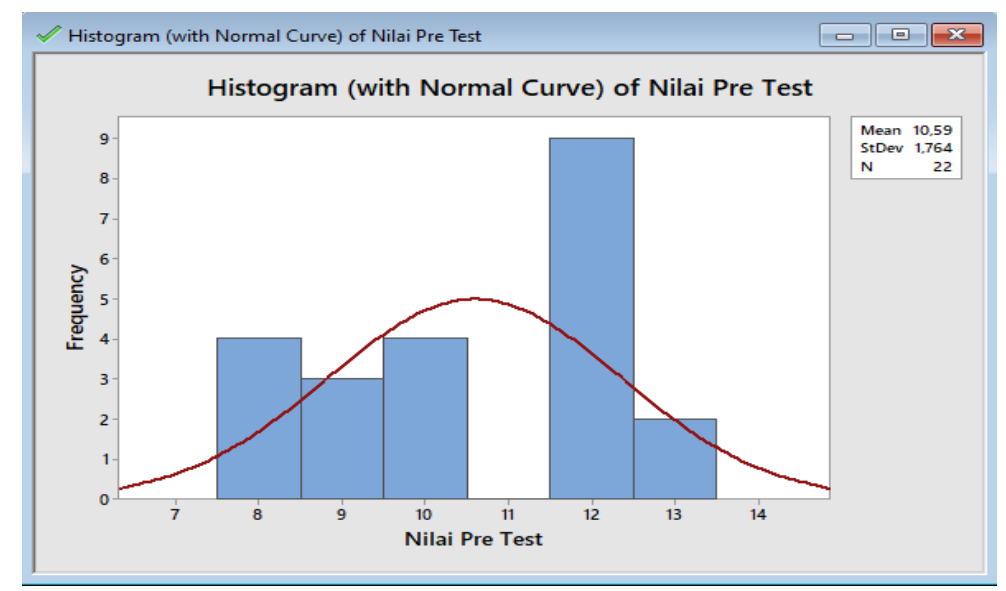

Gambar 2. Pie Chart Nilai Pre Test 


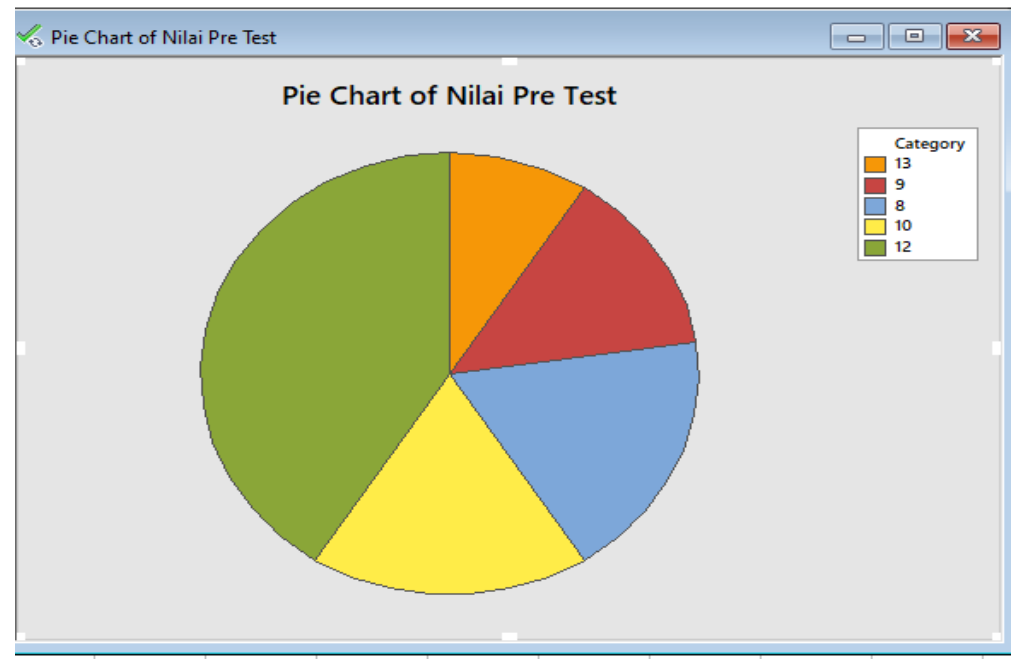

Interpretasi Output :Prosentase nilai 8(18,2\%),nilai 9(13,6\%),nilai 10(18,2\%),nilai 12 (40,9\%),nilai 13(9,1\%) dengan rata rata jawaban benar dari 22 peserta yang mengikuti Pre test adalah 10,591 .

\section{Hasil Post Test.}

Descriptive Statistics: Nilai Post Test

Variable $\quad \mathrm{N} \mathrm{N}^{*}$ Mean SE Mean StDev Minimum Q1 Median Q3

$\begin{array}{lllllllll}\text { Nilai Post Test } 4 & 0 & 13,500 & 0,645 & 1,291 & 12,000 & 12,250 & 13,500 & 14,750\end{array}$

Variable Maximum Skewness Kurtosis

Nilai Post Test $\quad 15,000 \quad 0,00 \quad-1,20$

Gambar 3. Histogram Sebaran Jawaban Benar Post Test.

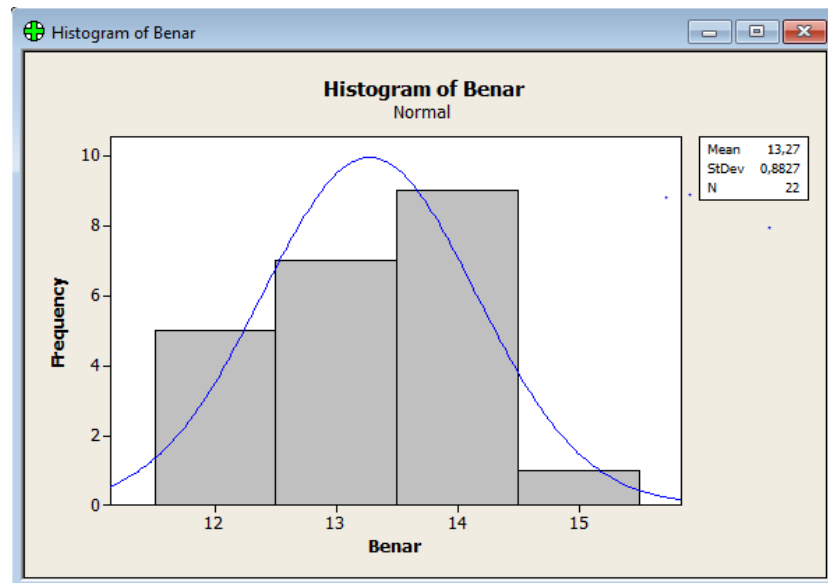

Gambar 4.Pie Chart Nilai Post Test 


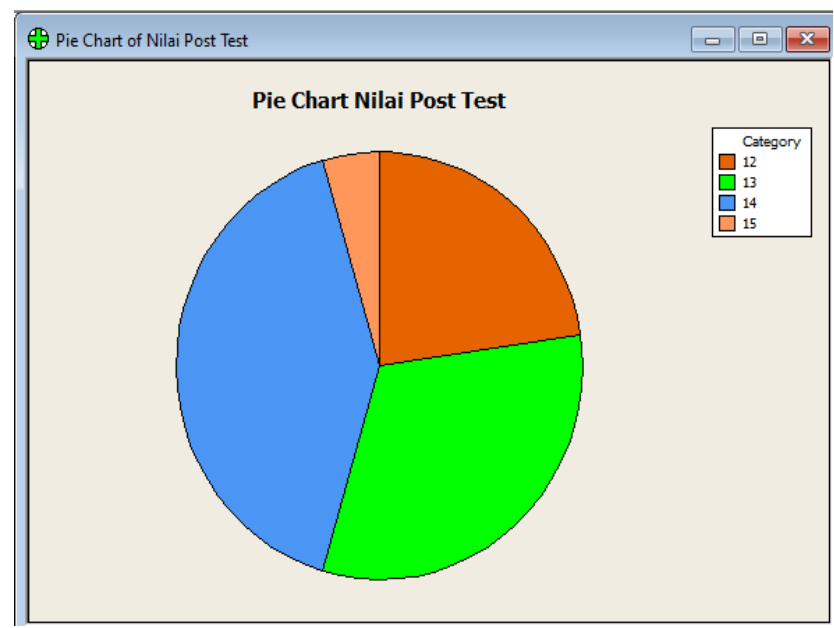

Interpretasi Output :Prosentase nilai 12(22,7\%),nilai 13(31,8\%),nilai 14(40,9\%),nilai 15(4,5\%), dengan rata rata jawaban benar dari 22 peserta yang mengikuti Pre test adalah 13,5.Adapun pertanyaan-pertanyaan kuesioner disajikan seperti pada Tabel .2. berikut.

Tabel.2.Kuesioner Pelatihan PKM

\begin{tabular}{|c|c|c|c|c|c|c|}
\hline No & Pernyataan & $\begin{array}{l}\text { Sangat } \\
\text { tidak } \\
\text { setuju } \\
\text { (1)STS }\end{array}$ & $\begin{array}{l}\text { Tidak } \\
\text { setuju } \\
\text { (2)TS }\end{array}$ & $\begin{array}{l}\text { Ragu } \\
\text { ragu } \\
(3) R R\end{array}$ & $\begin{array}{c}\text { Setuju } \\
\text { (4)S }\end{array}$ & $\begin{array}{l}\text { Sangat } \\
\text { setuju } \\
\text { (5)SS }\end{array}$ \\
\hline 1 & $\begin{array}{l}\text { Pelatihan yg diselenggarakan } \\
\text { harus direncanakan dan } \\
\text { dipersiapkan dengan matang. }\end{array}$ & & & & & \\
\hline 2 & $\begin{array}{l}\text { Materi dan pengajar pelatihan } \\
\text { yang saya ikuti sesuai dengan } \\
\text { kebutuhan. }\end{array}$ & & & & & \\
\hline 3 & $\begin{array}{l}\text { Sistem yang diberikan pada } \\
\text { penyelenggaraan pelatihan } \\
\text { sesuai dengan kebutuhan. }\end{array}$ & & & & & \\
\hline 4 & $\begin{array}{l}\text { Jenis pelatihan yang saya ikuti } \\
\text { sudah sesuai dengan } \\
\text { kebutuhan. }\end{array}$ & & & & & \\
\hline 5 & $\begin{array}{l}\text { Perlu adanya evaluasi } \\
\text { pelaksanaan pelatihan sebagai } \\
\text { acuan dimasa akan datang. }\end{array}$ & & & & & \\
\hline 6 & $\begin{array}{l}\text { Pelatihan yang saya ikuti } \\
\text { menambah pengetahuan dan } \\
\text { keahlian. }\end{array}$ & & & & & \\
\hline 7 & $\begin{array}{l}\text { Pelatihan yang saya ikuti } \\
\text { sangat bermanfaat bagi saya } \\
\text { dan mempunyai kontribusi } \\
\text { yang cukup tinggi dalam } \\
\text { membantu } \\
\text { pekerjaan. }\end{array}$ & & & & & \\
\hline 8 & \begin{tabular}{lccc} 
Pelatihan & yang & saya & ikuti \\
mampu & \multicolumn{3}{c}{ meningkatkan } \\
ketrampilan & bagi & diri & sendiri
\end{tabular} & & & & & \\
\hline
\end{tabular}




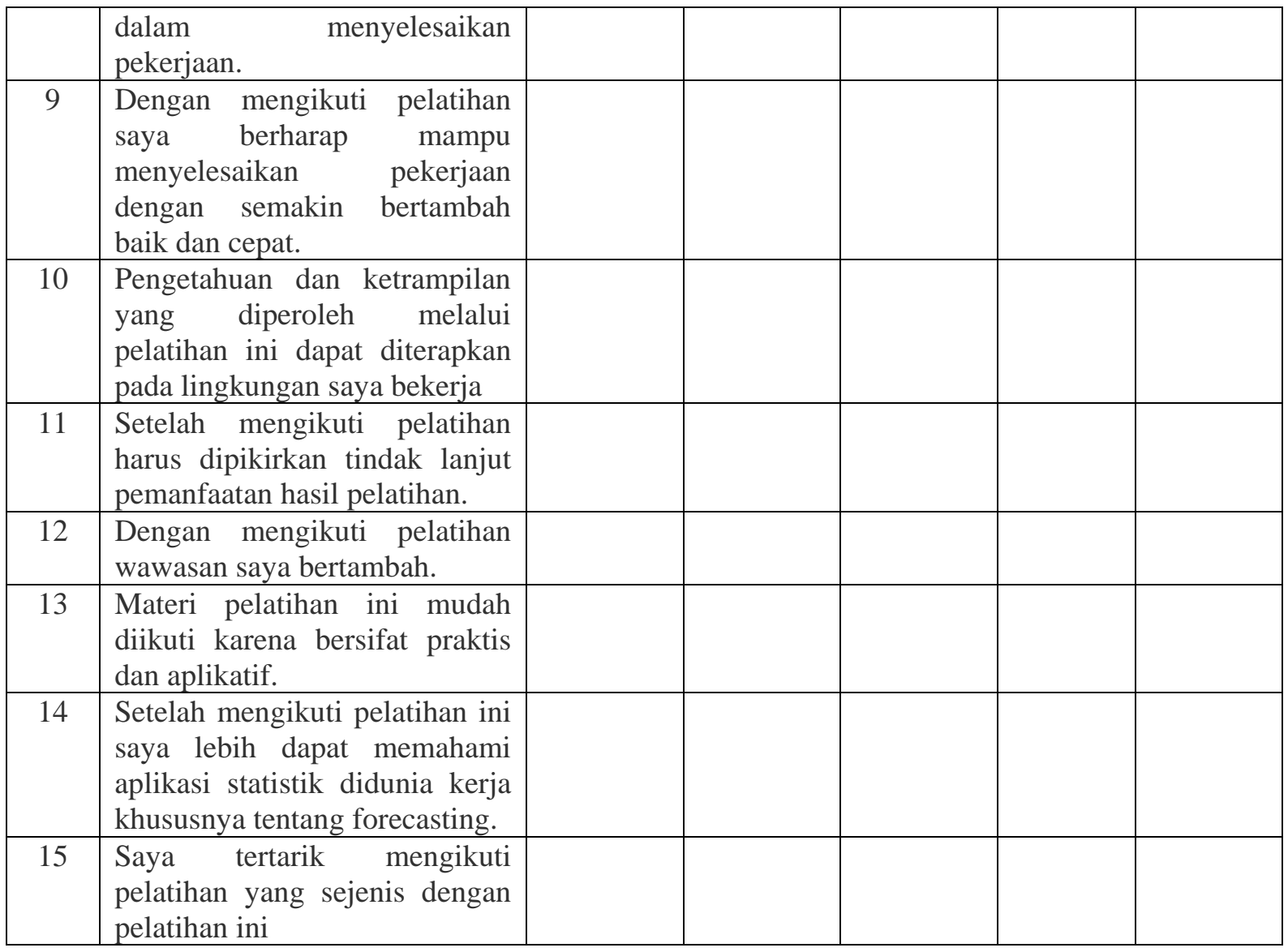

Analisis hasil kuesioner :

Tabel 3. Total Score Nilai \& Nilai Indeks Untuk Tiap Pertanyaan Kuesioner.

\begin{tabular}{|c|c|c|c|c|c|c|c|c|}
\hline \multirow{2}{*}{$\begin{array}{c}\text { Pertanyaan } \\
\text { Kuesioner } \\
\text { No. }\end{array}$} & \multicolumn{5}{|c|}{ Jumlah Peserta } & \multirow{2}{*}{$\begin{array}{c}\text { Jumlah } \\
\text { Responden }\end{array}$} & \multirow{2}{*}{$\begin{array}{c}\text { Total } \\
\text { Score } \\
\text { Nilai }\end{array}$} & \multirow{2}{*}{$\begin{array}{c}\text { Nilai Indeks } \\
\text { (\%) }\end{array}$} \\
\hline & STS(1) & $\mathrm{TS}(2)$ & RR(3) & $S(4)$ & SS(5) & & & \\
\hline 1 & 0 & 0 & 10 & 4 & 8 & 22 & 86 & 0,78181818 \\
\hline 2 & 1 & 2 & 6 & 5 & 8 & 22 & 83 & 0,75454546 \\
\hline 3 & 3 & 1 & 8 & 6 & 4 & 22 & 73 & 0,66363636 \\
\hline 4 & 2 & 2 & 6 & 8 & 4 & 22 & 76 & 0,69090909 \\
\hline 5 & 2 & 2 & 7 & 5 & 6 & 22 & 77 & 0,7 \\
\hline 6 & 0 & 0 & 4 & 8 & 10 & 22 & 94 & 0,85454546 \\
\hline 7 & 1 & 1 & 4 & 8 & 8 & 22 & 87 & 0,79090909 \\
\hline 8 & 0 & 0 & 2 & 8 & 12 & 22 & 98 & 0,89090909 \\
\hline 9 & 0 & 0 & 4 & 6 & 12 & 22 & 96 & 0,87272727 \\
\hline 10 & 0 & 0 & 4 & 8 & 10 & 22 & 94 & 0,85454546 \\
\hline 11 & 1 & 2 & 5 & 8 & 6 & 22 & 82 & 0,74545455 \\
\hline 12 & 0 & 0 & 4 & 6 & 12 & 22 & 96 & 0,87272727 \\
\hline 13 & 1 & 4 & 6 & 6 & 5 & 22 & 76 & 0,69090909 \\
\hline 14 & 1 & 2 & 2 & 9 & 8 & 22 & 87 & 0,79090909 \\
\hline 15 & 0 & 0 & 4 & 8 & 10 & 22 & 94 & 0,854545455 \\
\hline
\end{tabular}


Berdasarkan hasil perhitungan Nilai Indeks seperti tersaji di Tabel 3,diperoleh kesimpulan bahwa:rata-rata Nilai Indeks dari ke 15 pertanyaan kuesioner adalah 0,787272727 yang jika di interpretasikan dalam interval penilaian artinya peserta "setuju" akan pendapat dari setiap pertanyaan yang ada di kuesioner.

\section{SIMPULAN}

Berdasarkan uraian pada Hasil dan Pembahasan paper ini, dapat disimpulkan beberapa point:

- progam ini terbukti dapat meningkatkan pemahaman peserta mengenai forecasting diperancangan produk terlihat dari rata rata jawaban benar Pre test sebesar 10,591 menjadi 13,5 dengan skala penilaian 15 .

- Jawaban peserta terhadap pertanyaan kuesioner memberikan indeks penilaian sebesar 78,72\% Skala Likert yang artinya rata-rata peserta memberikan jawaban setuju terhadap pernyataan : Pelatihan yg diselenggarakan harus direncanakan dan dipersiapkan dengan matang, Materi dan pengajar pelatihan yang saya ikuti sesuai dengan kebutuhan, Sistem yang diberikan pada penyelenggaraan pelatihan sesuai dengan kebutuhan, Jenis pelatihan yang saya ikuti sudah sesuai dengan kebutuhan, Perlu adanya evaluasi pelaksanaan pelatihan sebagai acuan dimasa akan datang, Pelatihan yang saya ikuti menambah pengetahuan dan keahlian, Pelatihan yang saya ikuti sangat bermanfaat bagi saya dan mempunyai kontribusi yang cukup tinggi dalam membantu melaksanakan pekerjaan, Pelatihan yang saya ikuti mampu meningkatkan ketrampilan bagi diri sendiri dalam menyelesaikan pekerjaan, Dengan mengikuti pelatihan saya berharap mampu menyelesaikan pekerjaan dengan semakin bertambah baik dan cepat, Pengetahuan dan keterampilan yang diperoleh melalui pelatihan ini dapat diterapkan pada lingkungan saya bekerja, Dengan mengikuti pelatihan wawasan saya bertambah, Materi pelatihan ini mudah diikuti karena bersifat praktis dan aplikatif, Setelah mengikuti pelatihan ini saya lebih dapat memahami aplikasi statistik didunia kerja khususnya tentang forecasting, Saya tertarik mengikuti pelatihan yang sejenis dengan pelatihan ini.

\section{DAFTAR PUSTAKA}


Arikunto, Suharsimi. 2010. Prosedur Penelitian Suatu Pendekatan Praktek. Edisi Revisi 2010. Jakarta : Rineka Cipta.

Argyrous, G.2011. Statistics for Research: With a Guide to SPSS. Third Edition. USA, California 91320 A.

Nisa, U. M. 2017. Metode Praktikum untuk Meningkatkan Pemahaman dan Hasil Belajar Siswa Kelas

V MI YPPI 1945 Babat pada Materi Zat Tunggal dan Campuran. Proceeding Biology Education

Conference. 14(1) 62-68.

Royani, I., Mirawati, B., dan Jannah, H, 2018. Pengaruh Model Pembelajaran Langsung Berbasis Praktikum Terhadap Keterampilan Proses Sains dan Kemampuan Berpikir Kritis Siswa. Prisma Sains: Jurnal Pengkajian Ilmu dan Pembelajaran Matematika dan IPA IKIP Mataram. 6(2) 46-55.

Iman Permana Maksum, Firdausi Permata Ummu Latifah, Jamaludin Al-Anshori, Saadah Diana $\quad$ Rachman. Upaya Peningkatan Pemahaman Ilmu Kimia dan Aplikasinya Melalui Metode Sosialisasi dan Praktikum. Jurnal Pengabdian kepada Masyarakat Unpad Vol. 4, No. 6, $\quad$ Desember 2019: 129 - 132 ISSN 1410-5675 ; eISSN 2620-8431.

Suhar Janti, Analisis Validitas Dan Reliabilitas Dengan Skala Likert Terhadap Pengembangan SI/TI Dalam Penentuan Pengambilan Keputusan Penerapan Strategic Planning Pada Industri Garmen, Prosiding Seminar Nasional Aplikasi Sains \& Teknologi (SNAST) 2014 ISSN: 1979-911X Yogyakarta, 15 November 2014 A-155 A.

https://www.diedit.com/skala-likert/

https://teknikelektronika.com/pengertian-skala-likert-likert-scale-menggunakan-skala-likert/ https://naufansapoetra.blogspot.com/2015/11/cara-menghitung-kuesioner-skala-likert.html https://statistiser.blogspot.com/2014/12/tutorial-regresi-dengan-minitab_20.html 